15)

\title{
AS MICOTOXINAS E A SEGURANÇA ALIMENTAR NA SOJA ARMAZENADA
}

\author{
M.A. Oliveira ${ }^{1}$, I. Lorini ${ }^{2}$, C.A. Mallmann ${ }^{3}$ \\ 1- Embrapa Soja, Caixa Postal 231, CEP 86001-970 - Londrina - PR - Brasil, Telefone: (xx-43)3371-6282 - \\ Fax: (xx-43)3371-6100 - e-mail: (malvares@cnpso.embrapa.br); \\ 2- Embrapa Soja, Caixa Postal 231, CEP 86001-970 - Londrina - PR - Brasil, Telefone: (xx-43)3371-6268 - \\ Fax: (xx-43)3371-6100 - e-mail: (lorini@cnpso.embrapa.br); \\ 3- Universidade Federal de Santa Maria, LAMIC Prédio 44 - Asa Norte, 4 Andar, CEP 97119-900 - Santa Maria - RS \\ - Brasil, Telefone (xx55) 3220-8445 - e-mail: mallmann@lamic.ufsm.br.
}

\begin{abstract}
RESUMO - Micotoxinas associadas a grãos são uma das principais causas de não conformidade em relação a alimentos seguros enquanto que impurezas e/ou matérias estranhas podem estar associadas a sua maior incidência. Amostras de grãos de soja e suas respectivas impurezas foram avaliadas na recepção e na expedição na Unidade de Assaí, da Cooperativa Integrada, na safra 2008/2009. Os resultados mostraram baixa probabilidade de ocorrência de micotoxinas em grãos de soja quando armazenados de forma correta. Entretanto, a grande fonte de contaminação por aflatoxina e zearalenona são as impurezas e/ou matérias estranhas permitidas na legislação brasileira até o limite de $1 \%$.
\end{abstract}

ABSTRACT - Mycotoxins are an important contaminant on grains mainly on the impurities which coming with from the field during harvesting. Samples of soybean grain and their impurities were taken at reception of storage unit, during storage period and at delivering to industries for processing from the farmers cooperative Integrada storage unit of Assai, PR crop season 2008/2009. Results showed that soybean grains when stored properly have low probability of being contaminated with mycotoxins, however the major source of contamination by aflatoxin and zearalenone were impurities allowed at a rate of $1 \%$ by Brazilian legislation.

PALAVRAS-CHAVE: armazenagem de grãos; segurança alimentar; Glycine max,toxinas.

KEYWORDS: grain storage; food safety; Glycine max, toxins.

\section{INTRODUÇÃO}

Nas Unidades Armazenadoras de Grãos (UAGs) as operações de pré-armazenamento incluem colheita, transporte, recepção, pré-limpeza, secagem, limpeza ou seleção e expurgo preliminar. Nem sempre são realizadas todas estas operações, entretanto, a pré-limpeza e a secagem são geralmente compulsórias (Elias \& Oliveira, 2009).

Os grãos são porosos e ao serem armazenados se comportam como uma massa de grãos. Assim sendo, a presença de impurezas e/ou matérias estranhas podem formar partículas menores que os espaços intergranulares diminuindo a porosidade, dificultando a aeração da massa de grãos e comprometendo a qualidade durante o armazenamento. 


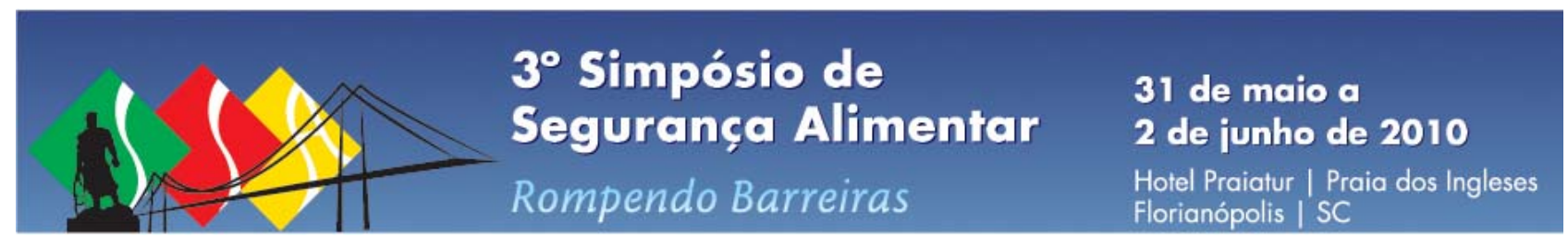

Nas UAGs são armazenados os grãos com a menor quantidade possível de impurezas e/ou matérias estranhas em silos/graneleiros. As impurezas e/ou matérias estranhas são separadas durante as operações de pré-armazenamento e estocadas em sacarias. No processo de expedição da soja essas impurezas e/ou matérias estranhas podem ser misturadas novamente à massa de grãos, até o limite de 1\% permitido pela legislação brasileira.

Micotoxinas associadas a grãos são uma das principais causas de não conformidade em relação a alimentos seguros enquanto que impurezas e/ou matérias estranhas podem estar associadas a sua maior incidência. As principais espécies de fungos toxigênicos com capacidade de produzir micotoxinas são aquelas dos gêneros Aspergilus, Penicillium e Fusarium.

Em grãos e produtos processados de soja, as micotoxinas relatadas são: aflatoxinas (B1, B2, G1, G2), deoxinivalenol, nivalenol, ocratoxina A e zearalenona, que comprometem a segurança do alimento (Gonçalez et al., 2001; Sassahara et al., 2003; Martinelli et al., 2004).

O objetivo deste trabalho foi verificar a presença de aflatoxinas (B1, B2, G1, G2), deoxinivalenol, nivalenol, ocratoxina A e zearalenona em grãos de soja e nas impurezas e/ou matérias estranhas, na Unidade de Recebimento de Grãos de Assaí/PR, pertencente à Cooperativa Integrada, durante as etapas de recepção e final da armazenagem (expedição) da safra 2008/2009.

\section{MATERIAL E MÉTODOS}

Durante a etapa de recepção, $100 \mathrm{~g}$ de amostras separadas de soja transgênica, soja convencional e suas respectivas impurezas e/ou matérias estranhas foram retiradas a cada 30 minutos, após a etapa de prélimpeza. Assim sendo, em cada dia de amostragem foram retiradas amostras compostas, que quarteadas na Embrapa Soja deram origem às seguintes amostras simples:

Amostra 1 - Soja convencional recepcionada dia 16/03/2009;

Amostra 2 - Soja convencional recepcionada dia 04/04/2009;

Amostra 3 - Soja transgênica recepcionada dia 05/03/2009;

Amostra 4 - Soja transgênica recepcionada dia 04/04/2009;

Amostra 5 - Impurezas e/ou matérias estranhas de soja convencional recepcionada dia 16/03/2009;

Amostra 6 - Impurezas e/ou matérias estranhas de soja convencional recepcionada dia 04/04/2009;

Amostra 7 - Impurezas e/ou matérias estranhas de soja transgênica recepcionada dia 05/03/2009;

Amostra 8 - Impurezas e/ou matérias estranhas de soja transgênica recepcionada dia 04/04/2009.

A retirada das amostras no final da armazenagem (etapa de expedição) ocorreu com a finalidade de avaliar as amostras com maior período de armazenamento e seguiu o mesmo padrão da etapa de recepção. Em relação às impurezas e/ou matérias estranhas, somente foram retiradas amostras do material transgênico, pois não havia mais as impurezas e/ou matérias estranhas para serem misturadas na expedição da soja convencional, que ficou armazenada por um período maior. Em cada dia de amostragem foram retiradas amostras compostas que quarteadas na Embrapa Soja deram origem às seguintes amostras simples:

Amostra 9 - Soja convencional expedida dia 05/10/2009;

Amostra 10 - Soja convencional expedida dia 26/09/2009;

Amostra 11 - Soja transgênica expedida dia 27/07/2009;

Amostra 12 - Soja transgênica expedida dia 27/07/2009;

Amostra 13 - Impurezas e/ou matérias estranhas de soja transgênica expedida dia 27/07/2009;

Amostra 14 - Impurezas e/ou matérias estranhas de soja transgênica expedida dia 27/07/2009.

As amostras foram acondicionadas em caixas de papelão com capacidade para armazenar $1 \mathrm{~kg}$ e em seguida encaminhadas para o Laboratório LAMIC - Laboratório de Micotoxinas, em Santa Maria/RS, credenciado pelo Ministério da Agricultura, Pecuária e Abastecimento e pela ANVISA, para realização das análises de micotoxinas. Foi utilizada a metodologia automatizada de extração e purificação em fase sólida e derivação com auxílio de um sistema de extração em fase sólida e processamento automatizado de amostras 


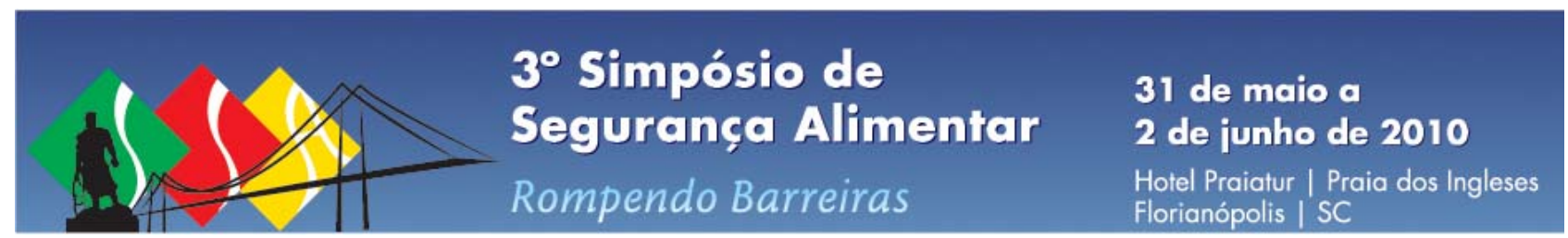

(ASPEC XL4). Para a quantificação foi utilizada a cromatografia líquida de alta eficiência (CLAE) com detecção por fluorescência para aflatoxinas, zearalenona e ocratoxina conforme Mallmann et al. (2000). Para a análise de Deoxinivalenol foi utilizada a CLAE/MS e para a de Nivalenol a GC/MS.

Os resultados foram expressos em $\mu \mathrm{g} / \mathrm{Kg}$. Os limites de quantificação e coeficiente de recuperação foram: AFB1 (Aflatoxina B1) $1 \mu \mathrm{g} / \mathrm{kg}$ e 94,5\%; AFB2 (Aflatoxina B2) $1 \mu \mathrm{g} / \mathrm{kg}$ e 80,0\%; AFG1 (Aflatoxina G1) $1 \mu \mathrm{g} / \mathrm{kg}$ e 88,5\%; AFG2 (Aflatoxina G2) $1 \mu \mathrm{g} / \mathrm{kg}$ e 88,1\%; ZEA (Zearalenona) $10 \mu \mathrm{g} / \mathrm{kg}$ e 85,0\%; DON

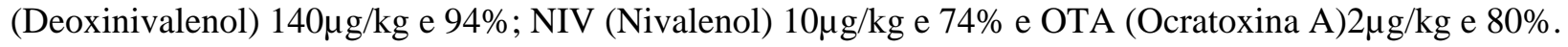

\section{RESULTADOS E DISCUSSÃO}

Na etapa de recepção a única micotoxina encontrada nos grãos de soja foi a aflatoxina B1, na concentração de $1 \mathrm{ppb}$, nas duas amostras de soja convencional. Nos grãos de soja transgênica não foi detectada nenhuma micotoxina (Figura 1).
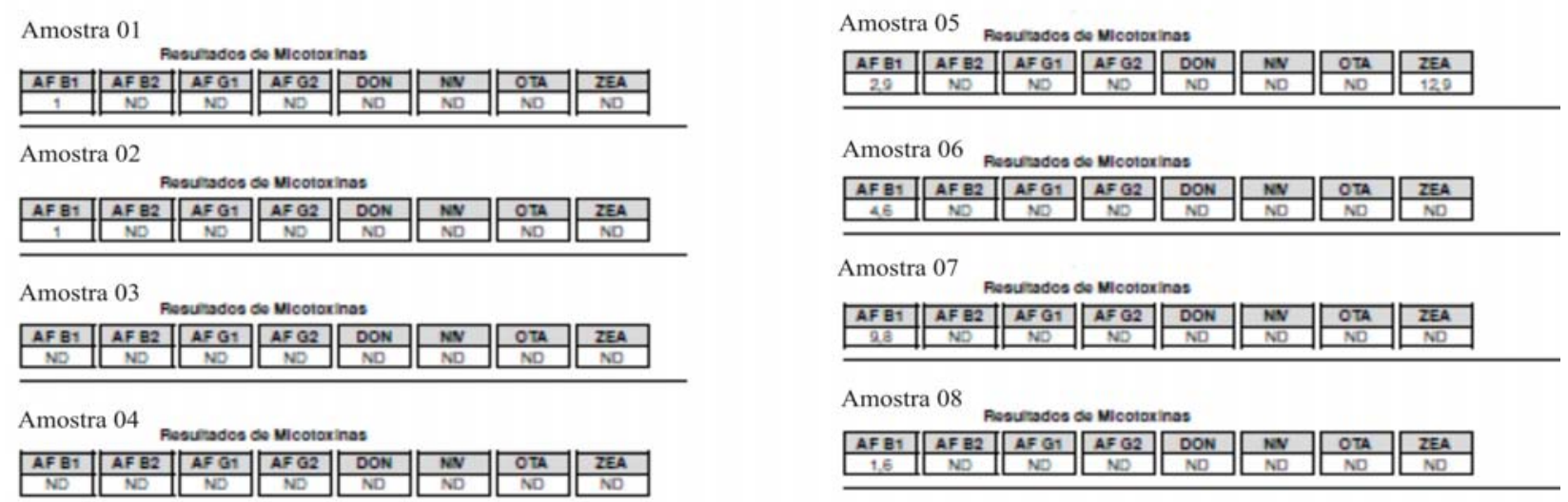

Figura 1 - Laudo fornecido pelo laboratório LAMIC, com os resultados de análise de micotoxinas em $\mu \mathrm{g} / \mathrm{Kg}$ nos grãos de soja e impurezas e/ou matérias estranhas, provenientes da recepção da UAG de Assaí, no estado do Paraná, na safra 2008/2009.

Em relação às impurezas e/ou matérias estranhas amostradas na etapa de recepção verificou-se a presença de aflatoxina B1 em todas as amostras, com valores variando de 1,6 a 9,8 ppb, valor este último muito próximo ao limite máximo para sementes oleaginosas que é $10 \mathrm{ppm}$ (consulta publica $\mathrm{n}^{\circ} 100$, de 21 de dezembro de 2009 da ANVISA). Foi verificada a presença de zearalenona em uma amostra de impurezas e/ou matérias estranhas. Na Europa, todos os produtos derivados de cereais devem apresentar limites inferiores a $100 \mathrm{ppb}$ de zearalenona, não existindo regulamentação desta micotoxina em soja e seus derivados (Freire et al., 2007). No Brasil não há legislação para essa micotoxina.

$\mathrm{Na}$ etapa de expedição verificou-se indiretamente que as condições de armazenagem foram ideais, devido à ausência de micotoxinas nos grãos de soja transgênicos e convencionais (Figura 2). Gonçalez et al. (2001) não encontrou nenhuma micotoxina em amostras de grãos de soja analisadas no Instituto Biológico entre os anos de 1989 e 1999. Entretanto, o mesmo Instituto relatou a presença de aflatoxinas em farelo de soja. A presença de aflatoxinas pode estar associada às condições de armazenamento do grão e do farelo de soja ou até mesmo na matéria prima.

Já em relação às impurezas e/ou matérias estranhas na etapa de expedição verificou-se a presença de aflatoxinas B1 e zearalenona em todas as amostras, sendo que a contaminação por zearalenona foi bastante expressiva em uma das amostras, superando o limite imposto pela Romênia para todos os alimentos, que é de 30 ppb (Legislação..., 2010) . 


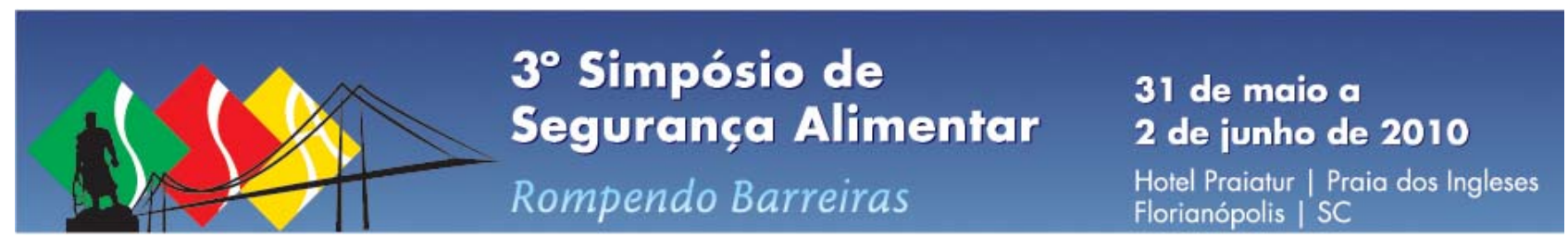

Amostra 09

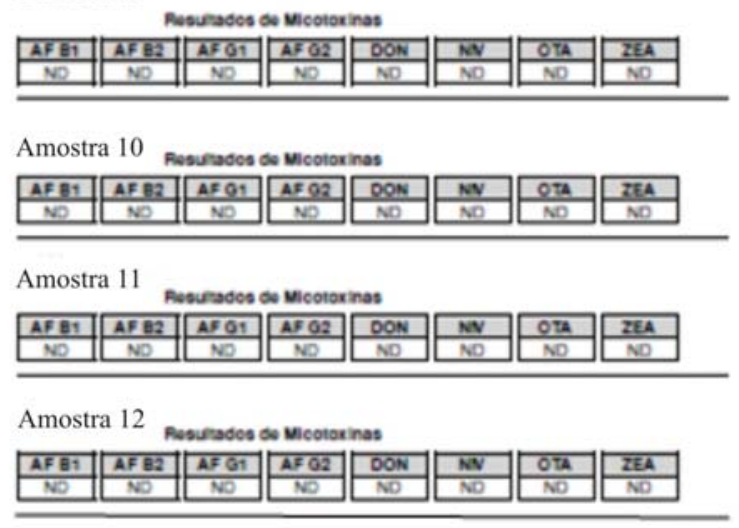

Amostra 13

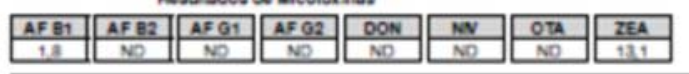

Amostra 14 Resuesdes de Micotorinas

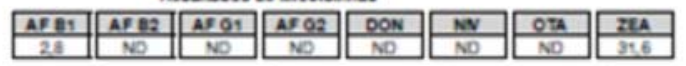

Figura 2 - Laudo fornecido pelo laboratório LAMIC, com os resultados de análise de micotoxinas em $\mu \mathrm{g} / \mathrm{Kg}$ nos grãos de soja e impurezas e/ou matérias estranhas, provenientes da expedição da UAG de Assaí, no estado do Paraná, na safra 2008/2009.

\section{CONCLUSÕES}

Os grãos de soja quando armazenados de forma correta apresentam baixa probabilidade de ocorrência de micotoxinas, entretanto a grande fonte de contaminação por aflatoxina B1 e zearalenona são as impurezas e/ou matérias estranhas permitidas na legislação brasileira até o limite de 1\%.

A legislação deve ser alterada e ser adotado o limite zero de impurezas , na etapa de expedição, visando garantir um alimento seguro na cadeia produtiva da soja.

\section{REFERÊNCIAS BIBLIOGRÁFICAS}

- ANVISA. Consulta Pública $n^{o}$ 100, de 21 de dezembro de 2009. Disponível em: < http://www.anvisa.gov.br>. Acesso em: 13 jan. 2010.

- ELIAS, M.C.; OLIVEIRA, M. Aspectos tecnológicos legais na formação de auditores técnicos do sistema nacional de certificação de unidades armazenadoras. Pelotas: Ed. Santa Cruz, 2009. 430p.

- FREIRE, F.C.O.; VIEIRA, I.G.P.; GUEDES, M.I.F.; MENDES, F.N.P. Micotoxinas: importância na alimentação e na saúde humana e animal. Fortaleza: Embrapa Agroindústria Tropical, 2007. 48p.

- GONÇALEZ, E.; PINTO, M.M.; FELICIO, J.D. Análise de micotoxinas no instituto biológico de 1989 a 1999. Biológico, São Paulo, v.63, n.1/2, p. 15-19, 2001.

- LEGISLAÇÃO sobre micotoxinas. Disponivel em: < http://www.micotoxinas.com.br/legisla.html>. Acesso em: 13 jan. 2010.

- MALLMANN, C.A.; ALMEIDA, C.A.A; MOSTARDEIRO, C.; STEFANON, E.B. Automation of the analytical procedure for simultaneous determination of aflatoxinas AFB1, AFB2, AFG1 and AFB2. In: CONGRESSO INTERNACIONAL DE MICOTOXINAS E FICOTOXINAS, 2000, Guarujá, SP. Anais... Guarujá, SP: IUPAC, 2000. v.1, p. 262.

- MARTINELLI, J.A.; BOCCHESE, C.A.C.; XIE, W; O’DONNELL, K.; KISTLER, H.C. Soybean oid blight and root rot caused by lineages of the Fusarium graminearum and the production of mycotoxins. Fitopatolologia Brasileira, v.29, n.5, p. 492-498, 2004.

- SASSAHARA, M.; YANAKA, E.K.; PONTES NETO, D. Ocorrência de aflatoxina e zearalenona em alimentos destinados ao gado leiteiro na Região Norte do Estado do Paraná. Semina: Ciências Agrárias, Londrina, v. 24, n. 1, p. 63-72, 2003. 